\title{
MODERNIDADE HIGIENISMO E GINÁSTICA EM SALVADOR/BA (1850-1920)
}

MODERNITY, HYGIENISM AND GYMNASTICS IN SALVADOR, BRAZIL (1850-1920)

MODERNIDAD, HIGIENISMO Y GIMNASIA EN SALVADOR/BAHIA (18501920)

\author{
Aline Gomes Machado*, Coriolano Pereira da Rocha Junior*
}

Palavras chave:

História.

Higienismo.

Práticas Corporais.

Ginástica.

Keywords:

History.

Hygiene.

Body Practices.

Gymnastics.

\begin{abstract}
Resumo: O século XIX representou um período de mudanças no Brasil, calcado em pensamentos como o Movimento Higienista. Este, com características biologizantes e centrado na racionalidade científica, influenciou diversos setores sociais, delineando almejadas práticas culturais, dentre elas, a ginástica. Este estudo aborda o pensamento higienista e sua relação com a ginástica em Salvador-BA, entre 1850 a 1920. Para o desenvolvimento optamos pela Nova História Cultural. O recorte temporal compreendeu o período entre a segunda metade do século XIX e as duas primeiras décadas do século XX, haja vista ter sido uma fase de construções de um projeto de sociedade moderna e higiênica. As fontes de pesquisa foram revistas e jornais publicados na Bahia, com circulação em Salvador. Como conclusão, apontamos que o caminho do progresso na capital baiana buscava relações estreitas com o higienismo e destacava a ginástica como prática dileta e símbolo moderno.
\end{abstract}

Palabras clave: Historia. Higienismo. Prácticas corporales. Gimnasia.
Abstract: The Nineteenth Century was a period of changes in Brazil, based on thoughts such as the Hygienist Movement. With its biologizing characteristics and centered on scientific rationality, the movement influenced several social segments, setting longed-awaited cultural practices such as gymnastics. This study addresses hygienist thinking and its relation to gymnastics in Salvador, Bahia, Brazil, between 1850 and 1920, using New Cultural History. The time frame comprises the period between the second half of the Nineteenth Century and the first two decades of the Twentieth Century, because that was a time for construction of a modern and hygienic society project. The sources were magazines and newspapers published in the state of Bahia. In conclusion, we point out that the path of progress in Salvador was closely related to hygienism and emphasized gymnastics' place as a modern practice and symbol.

Resumen: El siglo XIX representó un periodo de cambios en Brasil, basado en pensamientos como el Movimiento Higienista. Éste, con características biologizantes y centrado en la racionalidad científica, influyó en diversos sectores sociales, delineando deseadas prácticas culturales, entre ellas, la gimnasia. Este estudio trata sobre el pensamiento higienista y su relación con la gimnasia en Salvador, Bahia, entre 1850 y 1920. Para el desarrollo, optamos por la Nueva Historia Cultural. El recorte temporal comprendió el periodo entre la segunda mitad del siglo XIX y las dos primeras décadas del siglo XX, ya que se trataba de una fase de construcción de un proyecto de sociedad moderna e higiénica. Las fuentes fueron revistas y periódicos publicados en Bahia, con circulación en Salvador. Como conclusión, señalamos que el camino del progreso en la capital de Bahia buscaba estrechas relaciones con el higienismo y destacaba la gimnasia como práctica preferida y símbolo moderno.
* Universidade Federal da Bahia. Salvado, BA, Brasil. E-mail: liumaxado@hotmail.com; coriolanojunior@uol.com.br

Recebido em: 11-07-2019 Aprovado em: 28-01-2020 Publicado em: 23-02-2020 


\section{INTRODUÇÃO}

O século XIX representou um período de significativas mudanças no Brasil. Transformações nos setores econômicos, políticos, educacionais e culturais se configuraram como desejo e, até certo ponto, como realidade em vários lugares do país. O intuito principal desses movimentos transformadores, podemos dizer, era alcançar a modernidade característica dos países europeus com os o Brasil passou a estabelecer trocas materiais e simbólicas, para além das até então realizadas.

Dentre os pensamentos que nortearam esse processo de modernização nacional, apontamos aqui o Movimento Higienista, como categoria de centralidade para análise desse período. Com características biologizantes e centrado numa chamada racionalidade científica, esse movimento se estendeu e influenciou diversos setores sociais, delineando almejadas práticas cotidianas.

Os higienistas vislumbravam a necessidade de uma reeducação dos indivíduos, a fim de torná-los uma representação da modernidade. Machado (2017) aponta que se inicialmente, o discurso higienista estava voltado para os problemas estruturais das cidades e para as moléstias que acometiam a saúde da população, logo ele se voltou para os hábitos e comportamentos dos indivíduos, tornando-os empecilhos para a modernização da sociedade. Se faziam necessárias ações mais abrangentes, que conseguissem penetrar nas práticas cotidianas do povo, principalmente das camadas populares, pois as suas atitudes eram vistas como bárbaras, incivilizadas, muito destoantes do que se pretendia representar.

Neste sentido, os olhares da elite intelectual se voltaram para o sistema de educação, a fim de reelaborá-lo. Esse novo ideário de educação centrava-se em objetivos que contemplavam o controle das variáveis físicas, biológicas, mas que também buscavam uma retidão moral, uma disciplinarização necessária para atender as demandas sociais da época. Então, foi neste ponto que as práticas corporais passaram a ganhar lugar de destaque, por fornecerem ao corpo e a moral o remodelamento necessário aos padrões de civilidade e modernidade pretendidos.

Dentre as várias práticas corporais que faziam parte tanto do cotidiano de Salvador, quanto integravam o discurso higienista, destacamos aqui a ginástica como objeto de nosso estudo. Góis Junior (2013) expõe como o cuidar do corpo se estabeleceu como uma norma moral, tornando uma educação corporal, mais do que tudo uma educação moral, onde a Ginástica e a higiene se estabeleciam como ferramentas privilegiadas para o trato com o homem no século XIX.

Dito isto, este estudo aborda o pensamento higienista e sua relação com a ginástica. Nesse escopo, temos como objetivo central compreender o papel do Movimento Higienista na constituição das representações da ginástica como símbolo de prática moderna em Salvador entre os anos de 1850 e 1920. Para o desenvolvimento optamos pela perspectiva da Nova História Cultural, pois a mesma se encaixa na visão ontológica que possuímos do fazer científico.

Buscando distanciar-se da chamada Historia Tradicional, a Nova História Cultural (NHC), como conceitua Burke (2008), além de ampliar os horizontes 
de diálogos da história para com outras áreas, como a sociologia, antropologia, psicologia, passa a enxergar novos objetos de pesquisa, novas fontes, novas formas de se fazer história. As práticas culturais, como a ginástica, são exemplos desse novo olhar ao se constituírem como objetos de pesquisa, ganhando não apenas espaço, mas legitimidade na pesquisa histórica.

Nosso recorte temporal compreende o período entre a segunda metade do século XIX e as duas primeiras décadas do século XX, por ter sido uma fase de construções de um projeto de sociedade moderna e higiênica. Também porque, como asseguram Del Priore e Amantino (2013), se o debate sobre a importância de atividades físicas, como a ginástica, tendo em conta o desenvolvimento de hábitos higiênicos e disciplinado já exista desde o momento da independência, foi mesmo a partir de meados do século XIX que a ideia começou a se concretizar, se estendendo até as décadas iniciais do século XX. Assim, na esteira desse pensamento, delimitamos o marco temporal da pesquisa.

Utilizamos como fontes de pesquisa teses da Faculdade de Medicina da Bahia (FAMEB) apresentadas nos anos que compreendem o marco temporal do estudo (1850-1920); os jornais O Monitor com circulação entre os anos de 1876 a 1881, e Correio Mercantil: Jornal Politico, Commercial e Litterario com circulação entre os anos de 1836 e 1849; a revista A Escola: Revista Scientifica, Litteraria e Noticiosa com circulação em 1880 e o Relatorio de Trabalho do Conselho Interino do Governo do ano de 1856. Juntas essas fontes possibilitaram as análises e compreensões apresentadas nesse texto.

\section{ERA PRECISO MODERNIZAR}

O século XIX, no Brasil, representou um momento de mudanças significativas nos diversos setores. Via-se a efervescência de uma busca pela modernização do país. Civilização e modernidade se convertiam, neste momento, em palavras de ordem, virando instrumento de batalhas, além de fotografias de um ideal alentado.

No setor econômico, a grande novidade brasileira das primeiras décadas do período foi o surgimento da produção do café para exportação. A ampliação da produção cafeeira caminhou lado a lado com o aumento do hábito de consumir tal bebida entre as classes médias, cada vez mais numerosas nos Estados Unidos e na Europa. Segundo Fausto (1995, p. 54), essa “[...] seria uma característica importante das relações internacionais, que influenciaria profundamente a sociedade brasileira durante o século XIX e parte do século XX". O trânsito internacional, que essa produção cafeeira proporcionou, movimentou não só a vida econômica, mas a vida cultural do país.

Outros fatores modificadores da realidade brasileira estão relacionados com a criação de estradas de ferro, bancos e companhias de navegação. Essas instituições, em construção ou recém-construídas, atraiam a população que, em sua maioria, vivia no campo para as cidades, aumentando significativamente a aglomeração de pessoas nas capitais brasileiras. Tal fato trouxe impactos relativos à saúde e à higiene, como precariedade da coleta de lixo e dos sistemas de abastecimento de água e 
saneamento básico; condições miseráveis de habitação; hábitos morais e higiênicos questionáveis; péssimas condições de trabalho e alimentação. Tornou-se, também, mais expressivo o desemprego, a miséria e uma chamada 'malandragem'. Todas essas características formavam um ambiente ambíguo e conflituoso nas cidades do país.

Em Salvador, cenário deste estudo, todas essas mudanças e condições sociais aconteceram segundo as peculiaridades locais do estado e seu processo histórico. Leite (1996) assegura que em terras baianas figurava um sentimento de abandono e mesmo um ressentimento, ocasionados pela transferência da capital do país para o Rio de Janeiro. A este aspecto se somavam outros, como: a economia estadual em processo de encolhimento; uma grande parte da população recémliberta da escravidão, com dificuldade de ser absorvida por uma sociedade com marcas arraigadas de preconceitos, vivendo em péssimas condições; instalações sanitárias precárias e as epidemias de febre amarela e cólera de 1850 e 1855 assolando a população. Tais fatores acabaram por tornar o desenvolvimento dessa cidade bastante peculiar.

Tavares (2001) elucida, sobre as condições sanitárias, que Salvador era uma cidade sem nenhum tipo de cuidado com o esgoto, estava sempre suscetível a moléstias infectocontagiosas, que atacavam sua população. A camada negra e pobre da população era a mais massacrada pelas epidemias que tomavam a cidade, já que era mais exposta às situações de risco, de má higiene pelas péssimas condições de moradia e trabalho.

Este cenário estava muito aquém da imagem de modernidade que se queria ter na época, gerando motivações e aspirações por mudanças no sentido de civilizar a cidade de Salvador, mesmo que não fosse este um sentimento homogêneo ou hegemônico. A elite intelectual defendia as mudanças estruturais, educacionais e culturais, enquanto parte da aristocracia desejava manter o mandonismo colonial, mesmo com a ocorrência da República em 1889. Já a camada popular demonstrava resistências às mudanças, uma vez que tais mudanças desconsideravam a cultura local ao tomar como referências os padrões europeus, além de serem planejadas de forma vertical.

Nesse sentido, O cenário da capital baiana era heterogêneo até certo ponto, mas os discursos idealizadores de modernidade influenciaram as práticas cotidianas, de um modo geral. Esse processo se configurou de forma ambígua e peculiar, permitindo os tensionamentos de construções e desconstruções característicos da Modernidade. Logo, no seu ritmo, Salvador seguiu pela busca de tornar-se representação de modernidade como seguia o país como um todo. Segundo Marins (2008, p. 134) “[...] urgia civilizar o país, modernizá-lo, espelhar as potências industriais e democratizadas e inseri-lo, compulsória e firmemente, no trânsito de capitais, produtos e populações liderados pelo hemisfério norte".

Nessa conjuntura, as ciências, um símbolo de modernidade, viam-se em crescente desenvolvimento, em especial as ciências médicas, que ocupavam um

\footnotetext{
1 No Brasil a origem da malandragem está ligada às camadas negras e pobres da população, que no século XIX, em sua maioria, assumiam trabalhos temporários e, frequentemente, substituíam pelo ócio e pela vadiagem. Para mais informações ver Sousa (2008).
} 
lugar de destaque nas inscrições dos caminhos a serem seguidos para construção da modernidade soteropolitana. Souza e Barreto (2011) explicam como à abertura das primeiras escolas médico-cirúrgicas na Bahia e no Rio de Janeiro deflagraram um processo irreversível de institucionalização das ciências no Brasil, protagonizando em diversos momentos, projetos (alguns vitoriosos, outros rejeitados) que influenciaram a sociedade de um modo geral, uma vez que o desenvolvimento do conhecimento médico estava voltado às demandas sociais da época, e visavam não só solidificar posições no cenário acadêmico, como garantir a prática do conhecimento em circulação na academia.

A esse respeito Sá e Almeida (2012, p. 11) expõe:

O discurso de desenvolvimento na "Cidade da Bahia" do século XIX e meados do século XX, assentava-se igualmente no pressuposto de que a sciência possuía uma preposição especial para promover desenvolvimento. A sciência configura-se como 'um quê a mais' que caminha para o processo civilizatório. Quem se embebe dela, pois, superioridade moral e material, derivada do disciplinamento do temperamento, segundo o que defendia no período, seguiria firme em direção ao progresso.

Neste cenário baiano e nacional, um dos instrumentos constituintes do ideal de modernidade ficou conhecido como Movimento Higienista, que tinha como personagens principais os médicos e sua atuação voltada para a cidade e suas mazelas.

Se pensarmos na conjuntura sanitária precária, na qual estava imersa Salvador, como expomos anteriormente, os surtos de doenças e péssimas condições de vida, podemos compreender como as ciências médicas não só foram necessárias para lidar com esse contexto, mas como acharam terreno fértil para instauração e hegemonia dos seus saberes como norteadores do projeto civilizatório. Fato que não se distancia da realidade de outras cidades brasileiras, mas que é acentuado na capital baiana.

A atenção dada pelos higienistas às questões relativas à saúde da população colocava a ocorrência das mazelas sociais, de diversas doenças, e por vezes surtos dessas, como consequência de diversas variáveis, "como, por exemplo, as desigualdades econômicas; as precárias condições habitacionais; o alcoolismo; a má alimentação; a falta de exposição à luz solar; e o corpo fraco por falta de exercício físico" (COSTA; SANTOS; GÓIS JUNIOR, 2014, p. 275).

\section{O HIGIENISMO NA MODERNIDADE SOTEROPOLITANA}

A transição socioeconômica e o tom de desenvolvimento econômico de um segmento da sociedade acabaram por configurar um ambiente conflituoso, ambíguo e desigual nas cidades brasileiras. A industrialização ocasionou um movimento de inchaço das cidades que possuíam, em sua grande maioria, características coloniais, sem estrutura adequada para comportar, de forma satisfatória, um aumento significativo da população urbana, gerando problemas de ordem estética e higiênica.

2 O termo "Cidade da Bahia" foi utilizado para se referir a Salvador, capital do estado da Bahia, principalmente durante o século XIX e início do século XX. Atualmente, em menor grau, ainda é um recurso utilizado principalmente por intelectuais, como: Risério (2004); Sá e Almeida (2012); Tavares (2001). 
Nesse sentido, Pinheiro (2011), reafirma que nas cidades industrializadas, ou em processo de industrialização ocorreu um crescimento desmensurado e sem controle, potencializando um cenário de epidemias e de revoltas. Enquanto um grupo vivenciava os benefícios do capital, outro, que configurava a grande maioria da população, compunha a cena de infortúnios do país.

$\mathrm{Na}$ Bahia, enquanto o grupo que dominava a exportação e a atividade mercantil usufruía do esplendor da riqueza, o grande contingente populacional permanecia na dura realidade da pobreza. A esse respeito Risério (2004) afirma que a miséria foi, sem dúvida, um aspecto saliente e cruel da vida baiana no século XIX, em grande parte, como consequência da pouca flexibilidade à incorporação da mão-de-obra dos recém-libertos da escravidão. Aumentava o número de homens livres, mas estes não foram absorvidos em empregos remunerados, colocando-os numa condição de miséria e mendicância.

Souza e Barreto (2011, p. 49) afirmam que Salvador era uma cidade enferma, com taxas de morbidade e mortalidade muito elevadas, "[...] doenças como a disenteria, a difteria, a febre tifoide, a malária e a varíola acometiam os soteropolitanos com frequência, assumindo caráter quase endêmico".

O que se constituiu foi um cenário de caos e insalubridade, o que era muito distante do ideal de sociedade moderna e civilizada que se pretendia. Lembremos que a imagem de uma sociedade civilizada estava centrada na estética, na higiene, na ordem. Era preciso, então, mudar esse cenário e dentre os elementos norteadores do projeto de modernidade, o higienismo assumiu destaque.

Esse papel de referência do discurso higienista no processo de progresso do país justificava-se pelo pretendido triunfo da ciência, em especial da ciência médica. $\mathrm{Na}$ Bahia, a criação da Faculdade de Medicina marcou um período de cientificidade do estado que se industrializava, urbanizava e modernizava:

\begin{abstract}
Por tudo isso, pode-se afirmar que o contexto mais propício ao empreendimento das reformas modernizadoras que atingiram a "Cidade da Bahia" de meados do século XIX ao início do século XX, foi aquele que teve início tão logo foi implantada a Faculdade de Medicina da Bahia dado que, com a instalação dessa instituição impõe-se um novo regime de verdade o regime científico (SÁ; ALMEIDA, 2012, p. 14).
\end{abstract}

Assim, o discurso médico iria figurar no movimento de modernidade baiano, articulando o progresso, a necessidade de higiene. A exemplo disso temos a fala de Mathias de Campos Velho, na tese apresentada para conclusão do curso na Faculdade de Medicina da Bahia em 1886, aonde afirma que a higiene está:

\footnotetext{
[...] quasi sempre em razão directa com a civilização de um povo e constitue fonte de riqueza, porque concede dous thesouros preciosos, a saude e a ordem (p. 70).
}

[...] o homem civilisado tem sempre em vista: a hygiene geral ${ }^{3}$ (p. 67).

Campos Velho segue afirmando que alguns lugares da cidade mereciam mais atenção, como a Freguesia da Sé. Ele elucida que a criação de uma praça livraria as epidemias recorrentes nas cidades e assegurava que deveria se construir tais praças em vez de igrejas. "Temos aqui mais de cem igrejas, si se demolisse uma teríamos ainda muitas" (p. 65).

3 Optamos por manter a grafia original das fontes. 
Já Luiz de Oliveira Almeida, na tese intitulada Hygiene dos Pobres, reforçava a ideia do higienismo como caminho para o progresso, ao atentar para a necessidade de cuidados com a saúde dos pobres, "[...] do mesmo modo que os seos co-irmãos dos paizes adiantados, com a sã hygiene, base de todo progresso humano" (1908, p. 48).

Neste ponto, faz-se necessário discutir a abrangência e o sentido da higiene nesse período histórico. Sem dúvida, o chamado projeto higienista estava voltado para a saúde, mas não limitava (nem bastava para atingir os pretensos objetivos) a sua atenção e ação a esta questão. Leite (1996, p. 11) assegura que o projeto higienista procurou efetivação seguindo três orientações:

\begin{abstract}
Primeira, a implantação de uma política que agia combatendo diretamente os agentes naturais causadores das moléstias, assistindo aos doentes e criando instituições voltadas para o atendimento e prevenção dos enfermos. Segunda, a intervenção, por meio das reformas, na estrutura física das cidades. Terceira, a implementação de uma campanha de controle e modificação dos hábitos, costumes e modos de comportamento dos habitantes das cidades, especialmente as camadas populares.
\end{abstract}

Voltemos a nossa atenção à terceira orientação do projeto higienista que dizia respeito à mudança de hábitos, comportamentos da população. Se inicialmente, o discurso higienista estava voltado para os problemas estruturais das cidades e para as moléstias que acometiam a saúde da população, da mesma forma os hábitos e comportamentos das pessoas eram um entrave ao projeto de modernização da sociedade.

Então, se faziam necessárias ações mais abrangentes, que conseguissem penetrar nas práticas cotidianas do povo, principalmente das camadas populares, pois as suas ações eram vistas como bárbaras, incivilizadas, completamente contrárias ao que se desejava.

Certos hábitos, tradições, preferências por atividades lúdicas ou de entretenimento, como o uso da bebida alcoólica, as jogatinas e mesmo uma chamada malandragem, estavam fortemente arraigadas na alma da maior parte das pessoas, sobretudo, das camadas populares, que formavam majoritariamente a população baiana.

Sendo assim, este estrato da população destoava da camada elitizada, não só sob o ponto de vista socioeconômico, mas também no cultural, como aponta Leite (1996). Estes hábitos, segundo a percepção do médico Francisco Tavares da Cunha Melo, no ano de 1851, deveriam ser reprovados, tanto pelo aspecto moral, quanto pelo higiênico e eram tidos como os centrais para a geração e propagação de moléstias.

A sociedade baiana modernizada, que se pretendia construir, não possuía espaço para estas práticas anti-higiênicas, anticivilizadas. Era preciso construir um novo homem, "produzir sujeitos higiênicos, higienizados e higienizadores", como afirmam Costa, Góis Junior e Santos (2014, p. 275), ao analisarem outro cenário. Para isso, a atenção deveria se centrar na educação, como meio de incutir os valores, ideais higienistas.

Observemos na tese Hygiene Pedagogica, de Umbelino Heraclio Muniz Marques, como uma educação higiênica, digamos assim, virou símbolo de uma 
modernidade que, apesar de fundamental, não se viu no Brasil que caminhava para o século $X X$ :

A higiene pedagógica, que aliás age decisivamente sobre o desenvolvimento da creança, e sobre a conservação de sua saude, ainda nos paizes, mais adiantados deixa muito a desejar, quanto mais no Brazil, onde, em meteria de educação popular, tudo é palavra e só palavra (1886, p. 01).

Marques ainda afirma como uma educação higiênica "[...] adapta todas as potencias physycas, intellectuaes e moraes de cada individuo á função plena do papel que the esteja destinado desempenhar na coletividade" (1886, p. 02). Perceba como a preocupação estava centrada em tornar harmônica esta tríade das faculdades humanas, para que o sujeito pudesse desempenhar seu papel sem alterar a ordem social desejada, que neste caso era a ordem para um pretenso progresso e modernização.

Desta forma, comungamos com Melo Junior (2015) quando este afirma que se iniciava (ou intensificava) na Bahia um movimento visando à educação do povo, almejando não somente alfabetizar a população, mas, sobretudo, civilizar os costumes, moralizar as condutas e moldar comportamentos, de forma a alicerçar as bases da pretendida sociedade higiênica e moderna. Este movimento configurou as principais estratégias do projeto higienista.

\section{EDUCAÇÃO HIGIÊNICA E GINÁSTICA}

$\mathrm{Na}$ tentativa de disseminar hábitos higiênicos, a educação passou a se tornar um lugar possível para multiplicar os comportamentos desejados. Construiu-se então a necessidade de uma educação centrada no corpo, destacando a importância das práticas corporais sistematizadas como símbolo dos objetivos alentados para a sociedade.

Na mesma linha, asseveram Melo e Peres que "[...] as práticas corporais institucionalizadas constituíram-se em poderosas representações de valores, sensibilidades e desejos que permearam o ideário e imaginário da modernidade" (2014, p. 35).

Se o espelho de modernidade era, principalmente, os países europeus, ao tomar consciência da prática de exercício numa escola em Paris, um articulista do Correio Mercantil, já em 02 de junho de 1838 diz que "[...] uma igual escola, estabelecida no nosso paiz, seria como um modelo para se irem sucessivamente creando estabelecimentos da mesma espécie", e continua narrando os benefícios para uma sociedade que se pretendia civilizada.

Os higienistas constatavam as mazelas e colocavam a falta de "apuro na educação physica" no grupo dos elementos anti-higiênicos que prejudicavam a cidade de Salvador, como podemos perceber no Relatório do Conselho Interino de 1856, elaborado pelo secretário da Commissão de Hygiene Publica, Dr. Malaquias Avares dos Santos:

Nas demais comarcas existem também muitas causas de insalubridade, como sejam mais geralmente habitações húmidas, e mal arejadas, alimentação irregular e de má qualidade, pântanos de todos os gêneros, 
e nenhum apuro na educação physica; ao que demais se ajunctam muitos vicios na educação." moral e intelectual dos habitantes, o que se encontra ainda n'esta capital e mormente, nos seus suburbios (RELATÓRIO..., s.p.).

Dentro do conjunto de sentidos e práticas que compunham a ideia dos intelectuais baianos sobre a 'educação physica', uma tornou-se personagem principal: a ginástica. Francisco Candido da Silva Lobo diz que "a base da educação physica é a gymnastica” (1898, p. 03). Segundo Melo e Peres (2016), disciplina, saúde, higiene eram os princípios que integravam os discursos de defesa e valorização da ginástica, constantemente mobilizados por alguns médicos, dirigentes e intelectuais. Essas compreensões associadas pareceram compor o pensamento de médicos e articulistas baianos que recomendavam a prática da ginástica como basilar no processo de mudanças que o estado precisava passar.

De acordo com Melo (2007), antes da metade do século XIX, já era possível encontrar no país uma série de defesa e iniciativas de ensino e prática da ginástica. O Diario de Pernambuco em 16 de setembro de 1835 dedica um Editorial elucidando a importância da ginástica. O jornal Diario do Rio de Janeiro segue na esteira desse pensamento em publicação do ano de 1838. E o Recompilador Mineiro, em 1834, anuncia apresentação de José Chiarini, mestre da Escola Gymnastica. Esses exemplos confirmam e reforçam a ideia da ocorrência e defesa da ginástica como prática educativa no país, além de apontar para a ocorrência em outros espaços como Minas Gerais e Pernambuco, não apenas no eixo Rio-São Paulo, como comumente analisado.

Em Salvador, em anos mais a frente, em 08 de novembro de 1877, encontramos um anúncio no jornal $O$ Monitor afirmando que "[...] a gymastica, senhores, é essa educação forte que ensina a criança a vencer a si própria, o não succumbir nas dificuldades, a obedecer ao preceito, e sentido livre a fazer-se escrava do dever" (s.p.). Ratificando os argumentos aqui apresentados de que existia a defesa da ginástica, e nos fazendo inferir que existia consonância entre os discursos veiculados entre diferentes localidades do país.

Seguindo, Victor Melo (2007) aponta que os instrutores dessa prática eram normalmente militares, que ministravam sessões no interior de suas escolas específicas, ou no ensino da cidade, e imigrantes, que traziam dos países europeus o hábito da prática de atividades físicas, como forma de manutenção da saúde e controle moral. Esses ideais foram potencializando-se, também devido a contextualização complexa, paradoxal e ambígua em que se estruturava Salvador neste período estudado, o que demandava ações diversas que abrangessem toda a sociedade, principalmente os mais pobres e incultos.

Foi no caminho da construção de novas representações de indivíduos, e assim de uma nova realidade, que o discurso intelectual, com a figura do médico sendo central, passou a desmascarar as imagens indesejadas e cobrar do governo e da população baiana, ações adequadas (MACHADO, 2017). Ações que pudessem produzir de forma homogênea e padronizada o cenário de civilidade e modernidade em que caminhavam os países 'adiantados'. 
Nesse cenário, como argumentam Costa, Santos e Góis Junior (2014), a intervenção higiênica foi valorizada como remédio, não só para as condições de vida, mas também como força motriz de uma mudança de hábitos e mentalidades que se traduziam nos corpos. Desse modo, a higiene olhou para várias instituições da sociedade e, principalmente, para a Escola.

Neste sentido, afirma Melo Junior (2015):

Em geral, os médicos e articulistas se preocupavam com a imagem do país e a construção da nacionalidade de forma homogênea, geralmente dita civilizada. Transformar os costumes era um projeto ambíguo que ia desde educar a população através de práticas de higiene que preveniam doenças, como também regulamentar comportamentos nas vivências diárias que tinham como parâmetro as nações europeias e norte americana (p. 38).

Uma forma vislumbrada para atingir esses objetivos centrava-se na ampliação e melhoria do sistema educacional. Além da ampliação numérica, era necessário estabelecer melhorias na ação pedagógica, melhorias essas que deveriam ser concebidas a partir das noções de higiene, saúde e disciplina (MELO; PERES, 2016; TAVARES, 2001).

Nessa conjuntura, na tese apresentada a Faculdade de Medicina da Bahia, o médico Umbelino Heraclio Muniz Marques exemplifica qual deveria ser o caminho a seguir:

Emfim seja nossa preocupação principal acompanhar o movimento do nosso seculo n'este ramo essencial do aperfeiçoamento social, colloquemos a higyene pedagogica na primeira fila dos deveres governantes, como garantia á saude physica da geração nascente: não só está obrigado o estado pela carta constitucional a fornecer instrucção ao povo, como a proporcionar meios garantidores, quer da saude, quer do desenvolvimento organico de cada cidadão (1886, p. 41).

A educação era tida como um caminho para fazer com que os padrões higiênicos se multiplicassem e, assim, a civilidade. Para isso, se construiu o ideal de uma educação que desse destaque a importância das práticas corporais sistematizadas, no cenário escolar, como símbolo de um modelo de sociedade que se pretendia novo.

Os higienistas constatavam as mazelas e colocavam a falta de "apuro na educação physica" no grupo dos elementos anti-higiênicos, como podemos perceber no Relatório do Conselho Interino de 1856 elaborado pelo secretário da Commissão de Hygiene Publica, Dr. Malaquias Avares dos Santos:

\begin{abstract}
Nas demais comarcas existem também muitas causas de insalubridade, como sejam mais geralmente habitações húmidas, e mal arejadas, alimentação irregular e de má qualidade, pântanos de todos os gêneros, e nenhum apuro na educação physica; ao que demais se ajunctam muitos vicios na educação." moral e intelectual dos habitantes, o que se encontra ainda n'esta capital e mormente, nos seus suburbios (RELATÓRIO...,1856, p. 37).
\end{abstract}

Essa relação do exercício físico como elemento fundamental do higienismo para a educação do sujeito, ao menos no plano ideário, seguiu com o passar dos anos. Num artigo publicado em 10 de outubro de 1880, no periódico baiano A Escola 
- Revista scientifica, litteraria e noticiosa, temos o argumento de que "[...] pelo exercício, transformamos um homem ou animal a olhos vistos, afinal a educação física é a aplicação á cultura humana das leis da hygiene ou hygiene propriamente dita". Segue-se fazendo um apelo: "[...] senhores physiologistas, dainos o mais breve possível, sob uma forma resumida, satisfactoria, popular, um tractado completo de hygiene e de educação physica" (p. 22).

Podemos afirmar que este lugar de destaque que as práticas corporais sistematizadas ganharam progressivamente, com o passar do século XIX, mas principalmente nas últimas décadas, deveu-se ao fato destas carregarem em si valores que condiziam com a realidade da sociedade urbano-industrial, que estava se caminhando para construir. Essas práticas, como apontam Melo e Peres (2014), simbolizavam a necessidade de superação de limites, o extremo de determinadas situações, a valorização de tecnologia, a consolidação de identidades nacionais, a busca de uma emoção controlada, o exaltar de certo conceito de beleza. O seu desenvolvimento tem grande relação com uma sociedade que enfatizava as noções de produção, precisão, desempenho e disputa, com a sociedade moderna que se construía.

Diante dessa conjuntura, uma ideia que resume as noções de progresso, saúde e moral que se configuravam em torno das práticas corporais é expressa pelo Dr. Francisco Candido da Silva Lobo na tese Apontamentos Para o Estudo da Hygiene Escholar:

\begin{abstract}
Existem tão íntimas relações entre a organização physica, moral e intellectual, que o desprezo da educação physica não poderá deixar de reflectir-se nas outras nas outras, e é reconhecendo esta verdade que os governos dos paizes europeus e dos Estados-Unidos da America do Norte têm feito d'este assumpto objeto de sérios estudos, introduzindo-se anualmente n'estes paizes grandes melhoramentos com o fim de obter a educação physica mais perfeita possível (1898, p. 02).
\end{abstract}

Dentro do conjunto de sentidos e práticas que compunham a ideia desta 'educação physica', neste momento, uma tornou-se personagem principal: a ginástica. Francisco Candido da Silva Lobo na tese acima citada, diz que "[...] a base da educação physica é a gymnastica" (p. 03). Como vimos, Melo e Peres (2016) afirmam que disciplina, saúde, higiene eram os princípios que integravam os discursos de defesa e valorização da ginástica, constantemente, mobilizados por alguns médicos, dirigentes e intelectuais. Como já dito, tais compreensões também compuseram o pensamento de médicos e articulistas baianos, visto que estes recomendavam a ginástica, como uma atividade prioritária na formação corporal e moral dos sujeitos.

Os discursos intelectuais garantiam os porquês da importância desta prática, não apenas fundamentando os benefícios para o corpo e saúde, mas também para moral e formação do 'homem vigoroso'. Questionava-se inclusive a forma como os mais ricos educavam seus filhos. Sobre esta compreensão, Soares e Moreno (2015) asseveram que os "[...] problemas que esse modo de trabalhar o corpo buscava resolver também se voltavam para a melhoria e prevenção da saúde, a força de vontade, o desenvolvimento do caráter e a energia de viver" (p. 109).

Nessa linha, um articulista do Correio Mercantil em 02 de junho de 1838 (p.2) apontava que "[...] os mimos e branduras com que as pessoas mais ricas e poderosas 
custumão criar os filhos os fazem commummente aleminados e de débil compleição", e coloca a ginástica "com o exercício acertado" como corretiva desta situação, e segue garantindo que "a gymnastica, porém, nas cidades he absolutamente precisa, não para formar arlequins, como o para cuidado, mas para educar homens vigorosos".

Se os discursos de médicos e articulistas apontavam a importância de uma ginástica que atendesse à higiene, a realidade concreta nem sempre atendia completamente a este ideário. Melo e Peres (2016), ao analisarem a prática da ginástica no Colégio Abílio ${ }^{5}$ no Rio de Janeiro afirmam que nem sempre este ideal 'gímnico-higiênico' materializava-se ipsis litteris no cotidiano escolar, não só porque a ginástica era ressignificada pelos alunos a partir de suas necessidades concretas, como porque os próprios dirigentes faziam outros usos da prática, a partir de seus interesses específicos.

Ao olharmos para Bahia, identificamos que, neste período, a educação era restrita a uma pequena parcela da população. Segundo Tavares (2001, p. 271), na Bahia:

O Diretor-geral da Instrução em 1881, Romualdo Maria de Seixas Barroso registrou que havia 21.626 alunos matriculados em todas as escolas da Bahia, contraste imenso com a população de um milhão e meio de habitante.

Destarte, diante dos dados nos cabe refletir sobre os alcances concretos dessa ginástica higiênica, símbolo de modernidade, tão desejada e incentivada por médicos, articulistas, a elite intelectual soteropolitana.

\section{A GUISA DE CONCLUSÃO}

O desejo de modernização circulou entre um grupo, na realidade, uma elite intelectual composta por articulistas, políticos e, principalmente, médicos na capital baiana. Tal fato verticalizou as ações no sentido do progresso. Este grupo geria, orientava e executava os planos de civilidade. Isso não significa dizer que apresentavam consenso entre si, mas todos apontavam a melhoria no sistema educacional como um caminho para o progresso, e destacavam o lugar da ginástica como prática dileta e símbolo moderno.

Os discursos dessa elite intelectual, que defendia a prática da ginástica como uma ação educativa, estava assentado na ideia de racionalidade, civilização, moral, autonomia. Isso porque a prática era vista como capaz de fornecer meios para o uso comedido e prudente do corpo. Gestos e comportamentos econômicos, que fossem necessários, apenas. Uma ideia de racionalidade corporal que se relacionava com os processos de industrialização e do desenvolvimento urbano e científico, de uso adequado do tempo, uma visão de um chamado 'corpo-máquina'.

Assim, em Salvador, a elite intelectual também seguia o afã de tornar a ginástica uma técnica de educação do corpo, ensinando o comedimento, a contenção, o rigor consigo e com o outro, a igualdade de ritmos e gestos, tão necessários à vida urbana, reforçando a ideia do progresso relacionada ao controle, ao metódico, ao higiênico.

Certamente, não foi um processo homogêneo, nem estável, mas sim 
conflituoso e ambíguo. Existia sim, entre médicos e intelectuais, um claro desejo pela implementação e expansão da ginástica. Contudo, a sua abrangência real é questionável, uma vez que o próprio processo modernizador de Salvador se viu subjugado às questões concretas e culturais dessa cidade. Mas este é outro potencial debate que merece ser aprofundado, mas ao qual não vamos nos deter neste momento. O que podemos afirmar é que a ginástica, como ideal, constituise, em Salvador, nos sentidos de higiene, retidão moral e física, símbolos de uma modernidade pretendida, sem necessariamente ter se afirmado nos espaços escolares como uma prática educativa sistemática.

\section{REFERÊNCIAS}

ALMEIDA, Luiz de Oliveira. Hygiene dos Pobres. Salvador: FAMEB, 1908.

A ESCOLA - REVISTA SCIENTIFICA, LITTERARIA E NOTICIOSA. Salvador, out. 1880.

BURKE, Peter. O que é história cultural? 2. ed. Rio de Janeiro: Zahar, 2008.

CAMPOS VELHO, Mathias de. Etiologia do Cholera-Morbus: Medidas Sanitarias

Applicaveis Contra Sua Invasão e Propagação Nesta Cidade. Salvador: FAMEB, 1886.

CORREIO MERCANTIL. Salvador, jun. 1838.

COSTA, Luciene Henrique da; SANTOS, Marysol de Souza; GÓIS JUNIOR, Edivaldo. O discurso médico e a educação física nas escolas (Brasil, século XIX). Revista Brasileira de Educação Física e Esporte, v. 28, n. 2, p. 273-82, abr./jun. 2014.

DEL PRIORE, Mary; AMANTINO, Marcia. História dos Homens no Brasil. São Paulo: Unesp, 2013.

DIARIO DE PERNAMBUCO. Pernambuco, set. 1935.

DIARIO DO RIO DE JANEIRO. Rio de Janeiro, jun. 1838.

FAUSTO, Boris. História da Brasil. 2. ed. São Paulo: Editora da Universidade de São Paulo, 1995.

GÓIS JUNIOR, Edivaldo. Ginástica, higiene e eugenia no projeto de nação brasileira: Rio de Janeiro, século XIX e início do século XX. Movimento, v. 19, n. 1, p. 139-159, jan./mar. 2013.

LEITE, Rinaldo Cesar Nascimento. E A Bahia Civiliza-se: ideais de civilização e cenas de anti-civilidade em um contexto de modernização urbana, Salvador 1912-1916. 1996. 162 f. Dissertação (Mestrado em História) - Universidade Federal da Bahia, Salvador, 1996.

LOBO, Francisco Candido da Silva. Apontamentos Para o Estudo da Hygiene Escholar. FAMEB, Salvador, 1898.

MACHADO, Aline Gomes. A Ginástica Como Prática Educativa na Bahia (1850-1920). 2017. Dissertação (Mestrado) - Faculdade de Educação, Universidade Federal da Bahia, Salvador, 2017. 
MARINS, Paulo César Garcez. Habitação e vizinhança: limites da privacidade no surgimento das metrópoles brasileiras. In: SEVCENKO, Nicolau (org). História da vida privada no Brasil. São Paulo: Companhia das Letras, 2008. v. 3.

MARQUES, Umbelino Heraclio Muniz. Hygiene Pedagogica. Salvador: FAMEB, 1886.

MELO, Francisco Tavares da Cunha. Algumas Considerações Phycho-physiologicas acerca do Homem. Salvador: FAMEB, 1851.

MELO, Victor Andrade de. Dicionário do Esporte no Brasil: do século XIX ao início do século XX. Rio de Janeiro: Autores Associados, 2007.

MELO, Victor Andrade de. Uma diversão adequada? As touradas no Rio de Janeiro do século XIX (1870-1884). História, v. 32, p. 163-188, 2013.

MELO, Victor Andrade de; PERES, Carlos de Faria. A Gymnastica no Tempo do Império. Rio de Janeiro: 7Letras, 2014.

MELO, Victor Andrade de; PERES, Fabio de Faria. Relações entre ginástica e saúde no Rio de Janeiro do século XIX: reflexões a partir do caso do Colégio Abílio, 1872-1888. História, Ciência, saúde, v. 23, n. 4, p. 1133-1151, out./dez. 2016.

MELO JUNIOR, Djalma Santos. A Escolarização das Práticas Corporais em Meio a "Babel da Instrucção Publica Baiana: os confrontos em torno da gymanstica, musica e dança. Feira de Santana. 2015. Dissertação (Mestrado em História) - Departamento de Ciência Humanas e Filosofia, Universidade Estadual de Feira de Santana, 2015.

O MONITOR. Salvador, nov. 1877.

PINHEIRO, Eloísa Petti. Europa, França e Brasil: difusão e adaptação de modelos urbanos (França, Rio e Salvador). 2. ed. Salvador: EDUFBA, 2011.

RECOMPILADOR MINEIRO. Belo Horizonte, 1834.

RELATÓRIO DE TRABALHO DO CONSELHO INTERINO DO GOVERNO. Salvador, 1856.

RISÉRIO, Antonio. Uma história da cidade da Bahia. 2. ed. Rio de Janeiro: Versal Editores, 2004.

SÁ, Tania Regina Braga Torreão; ALMEIDA, José Rubens Mascarenhas de. A Cidade da Bahia de Meados do Século XIX e Início do Século XX: memória e patrimônio em uma cidade do capital. In: CONGRESSO INTERNACIONAL INTERDISCIPLINAR EM SOCIAIS E HUMANIDADES, 2012, Niterói-RJ. Anais [...]. Niterói-RJ, 2012.

SOARES, Carmen Lúcia; MORENO, Andrea. Dossiê - práticas e prescrições sobre o corpo: a dimensão educativa dos métodos ginásticos europeus. Revista Brasileira de Ciências do Esporte, v. 37, n. 2, p. 108-110, mar. 2015.

SOUSA, Venceslau Alves de. Malandragem e Cidadania: novas pistas. São Paulo, 2008. Tese (Doutorado em Ciências Sociais) - Pontifícia Universidade Católica de São Paulo, 2008.

SOUZA, Christiane Maria Cruz de; BARRETO, Maria Renilda Nery. História da Saúde na Bahia: instituições e patrimônio arquitetônico. Barueri: FIOCRUZ, 2011.

TAVARES, Luís Henrique Dias. História da Bahia. 10. ed. Salvador: EDUFBA, 2001. 
Apoio:

Fundação de Amparo à Pesquisa do Estado da Bahia (FAPESB). 